\title{
Hafnium isotope analysis of mixed standard solutions by multi-collector inductively coupled plasma mass spectrometry: an evaluation of isobaric interference corrections
}

\author{
Min Seok Choi, Chang-Sik Cheong ${ }^{*}$, Jeongmin Kim and Hyung Seon Shin
}

\begin{abstract}
Background: The Lu-Hf isotope system is widely used to decipher the crustal evolution and mantle differentiation of the Earth. The most critical point in obtaining accurate $\mathrm{Hf}$ isotope data is to correct the isobaric interferences of $\mathrm{Yb}$ and Lu imposed on the ${ }^{176} \mathrm{Hf}$ peak. In this study, we tested the validity of within-run correction protocol using MC-ICP-MS analysis of Hf standard solutions doped with Yb and Lu.
\end{abstract}

Findings: We found that the use of carefully selected $\mathrm{Yb}$ isotopic composition in the literature resulted in more reliable ${ }^{176} \mathrm{Hf} /{ }^{177} \mathrm{Hf}$ ratio. The ${ }^{176} \mathrm{Hf} /{ }^{177} \mathrm{Hf}$ ratios analyzed for a series of mixed $\mathrm{Hf}+\mathrm{Yb}+\mathrm{Lu}$ standard solutions could be quite accurately corrected for the mass bias and isobaric interferences. The systematic decreasing trend in the corrected ${ }^{176} \mathrm{Hf} /{ }^{177} \mathrm{Hf}$ ratios with increasing $\mathrm{Yb} / \mathrm{Hf}$ ratios, however, indicates that the mass bias effect cannot be completely removed by the exponential law for samples high in $\mathrm{Yb}$.

Conclusions: A close correlation of the calculated ${ }^{176} \mathrm{Yb} /{ }^{177} \mathrm{Hf}$ and ${ }^{176} \mathrm{Lu} /{ }^{177} \mathrm{Hf}$ ratios with the gravimetric values sheds light on the direct determination of inter-elemental isotope ratios without chemical purification.

Keywords: Lu-HF, MC-ICP-MS, Isobaric interference, Mass bias

\section{Introduction}

Out of six naturally occurring isotopes of hafnium $\left({ }^{174} \mathrm{Hf},{ }^{176} \mathrm{Hf},{ }^{177} \mathrm{Hf},{ }^{178} \mathrm{Hf},{ }^{179} \mathrm{Hf}\right.$ and $\left.{ }^{180} \mathrm{Hf}\right)$, radiogenic ${ }^{176} \mathrm{Hf}$ is produced by the ${ }^{\beta-}$ decay of ${ }^{176} \mathrm{Lu}$ with a half-life of 37.2 billion years in terrestrial samples (decay constant $\left.\lambda=1.865 \times 10^{-11} \mathrm{y}^{-1}\right)$ (Scherer et al. 2001). Hafnium is more incompatible than lutetium during partial melting of mantle peridotite and thus long-term enrichment of the former relative to the latter in the continental crust has yielded unradiogenic ${ }^{176} \mathrm{Hf} /{ }^{177} \mathrm{Hf}$ ratios compared with those in the depleted mantle (Patchett et al. 1981). In this respect, the Lu-Hf system has been effectively used to trace crustal evolution and mantle differentiation of the Earth since the early 1980s (Patchett et al. 1981; Patchett \& Tatsumoto 1980; Patchett

\footnotetext{
* Correspondence: ccs@kbsi.re.kr

Division of Earth and Environmental Sciences, Korea Basic Science Institute,
} Chungbuk 363-883, South Korea
1983). Early Lu-Hf works were majorly undertaken by thermal ionization mass spectrometry but recent advances in multi-collector inductively coupled plasma mass spectrometry (MC-ICP-MS) have revolutionized the analysis of Lu-Hf isotopes, especially when combined with laser-ablation micro-sampling techniques (Thirlwall \& Walder 1995; Griffin et al. 2000; Hawkesworth \& Kemp 2006).

Accurate ${ }^{176} \mathrm{Hf} /{ }^{177} \mathrm{Hf}$ ratio is obtained only after the contribution of isobaric interferences by rare earth elements $\mathrm{Yb}$ and $\mathrm{Lu}$ on the ${ }^{176} \mathrm{Hf}$ signal is carefully corrected (Woodhead et al. 2004; Iizuka \& Hirata 2005). This is particularly important where hafnium purification is unavailable prior to sample introduction to the ion source, as in the case of laser ablation analysis. The present study tests the validity of isobaric interference correction at mass 176 by using MC-ICP-MS analysis of $\mathrm{Hf}$ standard solutions doped with $\mathrm{Yb}$ and $\mathrm{Lu}$. As the precise values of $\mathrm{Yb}$ isotope ratios selected for the 
correction of mass bias and isobaric contribution critically concern the reliability of corrected ${ }^{176} \mathrm{Hf} /{ }^{177} \mathrm{Hf}$ ratio, previous reports on $\mathrm{Yb}$ isotopic abundances will also be evaluated.

\section{Instrumentation}

In this study, $\mathrm{Hf}, \mathrm{Yb}$ and $\mathrm{Lu}$ isotopic signals were measured by using a Neptune MC-ICP-MS installed at the Korea Basic Science Institute (KBSI) in Ochang. This instrument is a double focusing high-resolution ICP-MS equipped with eight motorized Faraday collectors and one fixed axial channel where ion beam intensities can be measured with either a Faraday collector or an ion counting electron multiplier. The gain calibration biases of the amplifiers are canceled out with the virtual amplifier design in which all Faraday collectors in a certain measurement are sequentially connected to all amplifiers. The Faraday collectors were statically set to simultaneously detect the required isotopes: ${ }^{172} \mathrm{Yb}$ (low 4), ${ }^{173} \mathrm{Yb}$ (low 3), ${ }^{175} \mathrm{Lu}$ (low 2), ${ }^{176}(\mathrm{Yb}+\mathrm{Lu}+\mathrm{Hf})$ (low 1), ${ }^{177} \mathrm{Hf}$ (axial), ${ }^{178} \mathrm{Hf}$ (high 1), ${ }^{179} \mathrm{Hf}$ (high 2) and ${ }^{180} \mathrm{Hf}$ (high 3), respectively. The ion beam intensities were optimized by adjusting the torch position, gas flows and ion focus settings. The sensitivity on ${ }^{180} \mathrm{Hf}$ was typically around $25 \mathrm{~V} / \mathrm{Hf} \mathrm{ppm}\left(10^{+11}\right.$ Sresistors $)$ in a low resolution (ca. 400) mode. Details of the other operational parameters are summarized in Table 1.

\section{Measurement of standard solutions}

The basic instrumental capability of the KBSI Neptune MC-ICP-MS was tested by using a JMC $475 \mathrm{Hf}$ standard solution with a concentration of $200 \mathrm{ng} \mathrm{ml}^{-1}$. The exponential law (Russel et al. 1978) was applied for mass bias

Table 1 MC-ICP-MS instrumentation and operational parameters

\begin{tabular}{ll}
\hline RF forward power & $1200 \mathrm{~W}$ \\
RF reflected power & $<2 \mathrm{~W}$ \\
Cooling gas & $15 \mathrm{~L} / \mathrm{min}$. \\
Auxiliary gas & $0.7 \mathrm{~L} / \mathrm{min}$. \\
Sample gas & $1.018 \mathrm{~L} / \mathrm{min}$. \\
Extraction & $-2 \mathrm{kV}$ \\
Focus & $-0.621 \mathrm{kV}$ \\
Acceleration voltage & $10 \mathrm{kV}$ \\
Interface cones & Nickel \\
Spray chamber & Quartz dual cyclonic \\
Nebulizer & ESI PFA MicroFlow \\
Sample uptake rate & $100 \mathrm{LL} / \mathrm{min}$. \\
Instrumental resolution & ca. 400 \\
Mass analyzer pressure & $3.2 \times 10^{-9}$ mbar \\
\hline
\end{tabular}

correction using ${ }^{179} \mathrm{Hf} /{ }^{177} \mathrm{Hf}=0.7325$ (Patchett et al. 1981). One run consists of 20 cycles, in which one cycle has an integration time of 4.194 s. The average ${ }^{176} \mathrm{Hf} /{ }^{177} \mathrm{Hf}$ ratio $(0.282167 \pm 0.000005, \mathrm{n}=5,2 \sigma$ S. E. $)$ agrees well with previous recommended values (Blichert-Toft et al. 1997; Nowell et al. 1998; Vervoort \& Blichert-Toft 1999) (Table 2). A range of shorter integration times $(0.161,0.262,0.524 \mathrm{~s})$ were tried with one block of 30 cycles $(n=3)$. All results of ${ }^{176} \mathrm{Hf} /{ }^{177} \mathrm{Hf}$ ratio are quite reproducible and accurate (Figure 1) and thus it is concluded that the isotopic composition of a small quantity of hafnium ( $<20 \mathrm{ng})$ could be analyzed with reasonable precision and accuracy in a short ( $<1$ minute) measurement time.

We also measured Hf isotope ratios of in-house standard solution JMC 14375, delivered from Alfa Aesar of Johnson Matthey Company (stock no. 14375, lot no. $83-084740 \mathrm{~F}$, plasma standard solution). The ${ }^{176} \mathrm{Hf} /{ }^{177} \mathrm{Hf}$ ratio of this standard solution $\left(300 \mathrm{ng} \mathrm{ml}^{-1} \mathrm{Hf}\right)$, measured with the same analytical design as that for the measurement of JMC 475 standard solution (20 cycles, $4.194 \mathrm{~s}$ integration) gave an average of 0.282228 $\pm 0.000005(\mathrm{n}=10,2 \sigma$ S. E.) (Table 3).

\section{Correction for isobaric interferences}

Several analytical strategies were suggested to correct the isobaric interferences by $\mathrm{Yb}$ and $\mathrm{Lu}$ on ${ }^{176} \mathrm{Hf}$ : (1) $\mathrm{Yb}$ is doped with $\mathrm{Hf}$ isotope standard solution, and then use revised $\mathrm{Yb}$ isotopic compositions that give correct ${ }^{176} \mathrm{Hf} /{ }^{177} \mathrm{Hf}$ ratio (Thirlwall \& Walder 1995; Griffin et al. 2000), (2) Determine the relationship between the Hf and $\mathrm{Yb}$ mass bias factors (Chu et al. 2002), (3) Yb mass bias factor is directly obtained from the $\mathrm{Yb}$ isotope ratios simultaneously measured with the $\mathrm{Hf}$ analysis (Woodhead et al. 2004; Iizuka \& Hirata 2005). The last protocol would be the most effective unless $\mathrm{Yb}$ signal intensities are so low that precise isotope ratios are unavailable, considering that the mass bias factor is not a constant value during the MC-ICP-MS measurement (Woodhead et al. 2004; Iizuka \& Hirata 2005). In this study, the isobaric interferences of ${ }^{176} \mathrm{Lu}$ and ${ }^{176} \mathrm{Yb}$

Table 2 Hf isotope ratios of JMC 475 standard solution

\begin{tabular}{|c|c|c|c|}
\hline${ }^{176} \mathrm{Hf} /{ }^{177} \mathrm{Hf}$ & $2 \sigma \mathrm{S} . \mathrm{E}$. & ${ }^{178} \mathrm{Hf} /{ }^{177} \mathrm{Hf}$ & $2 \sigma$ S. E. \\
\hline 0.282171 & 0.000014 & 1.467249 & 0.000024 \\
\hline 0.282153 & 0.000020 & 1.467270 & 0.000022 \\
\hline 0.282167 & 0.000014 & 1.467247 & 0.000018 \\
\hline 0.282174 & 0.000012 & 1.467248 & 0.000028 \\
\hline 0.282173 & 0.000019 & 1.467256 & 0.000022 \\
\hline \multicolumn{4}{|l|}{ Average } \\
\hline 0.282167 & 0.000005 & 1.467254 & 0.000008 \\
\hline
\end{tabular}



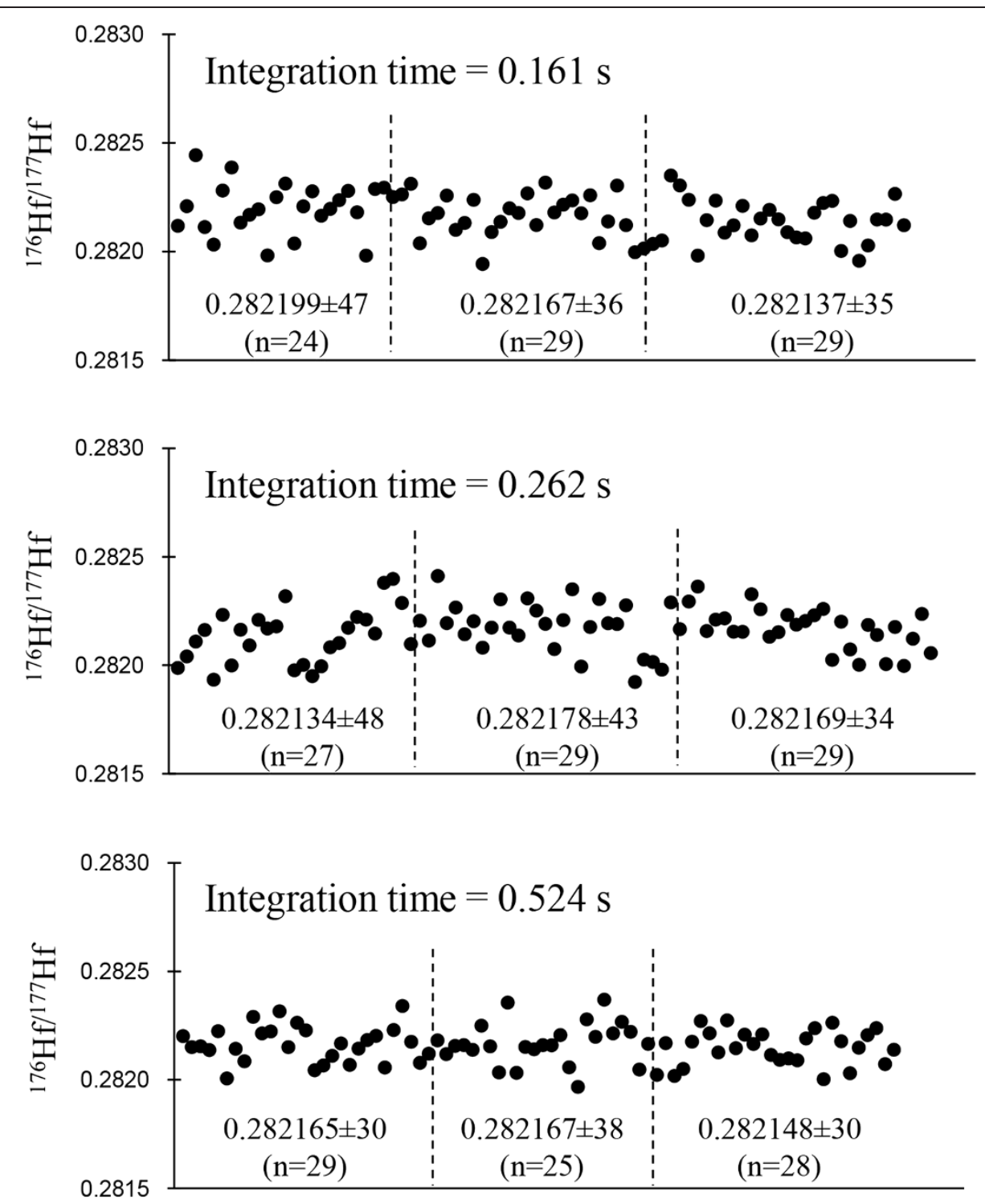

Figure 1 Hafnium isotope measurements of JMC 475 standard solution with integration times of $0.161,0.262$ and $0.524 \mathrm{~s}$.

on ${ }^{176} \mathrm{Hf}$ were directly estimated by monitoring the intensities of interference-free $\mathrm{Lu}$ and $\mathrm{Yb}$ signals as the following:

$$
\begin{aligned}
& { }^{176} \mathrm{Hf}_{\text {measured }}={ }^{176}(\mathrm{Hf}+\mathrm{Lu}+\mathrm{Yb})_{\text {measured }} \\
& \begin{array}{l}
-\left[{ }^{175} \mathrm{Lu}_{\text {measured }} \times\left({ }^{176} \mathrm{Lu} /{ }^{175} \mathrm{Lu}\right)_{\text {true }} \times\left(\mathrm{M}_{175} / \mathrm{M}_{176(\mathrm{Lu})}\right)^{\beta(\mathrm{Lu})}\right] \\
-\left[{ }^{173} \mathrm{Yb}_{\text {measured }} \times\left({ }^{176} \mathrm{Yb} /{ }^{173} \mathrm{Yb}\right)_{\text {true }} \times\left(\mathrm{M}_{173} / \mathrm{M}_{176}(\mathrm{Yb})\right)^{\beta(\mathrm{Yb})}\right]
\end{array}
\end{aligned}
$$

where $\beta(\mathrm{Lu})$ and $\beta(\mathrm{Yb})$ are respective exponential mass bias factors for $\mathrm{Lu}$ and $\mathrm{Yb}$, and "M" denotes the mass of the isotope. The $\beta(\mathrm{Hf})$ and $\beta(\mathrm{Yb})$ values were measured by monitoring ${ }^{179} \mathrm{Hf} /{ }^{177} \mathrm{Hf}$ and ${ }^{172} \mathrm{Yb} /{ }^{173} \mathrm{Yb}$ ratios for a mixed standard solution of which concentrations were $298.7 \mathrm{ng} \mathrm{ml}^{-1}$ for JMC $14375 \mathrm{Hf}, 30.4 \mathrm{ng} \mathrm{ml}^{-1}$ for
Table $3 \mathrm{Hf}$ isotope ratios of JMC 14375 standard solution

\begin{tabular}{llll}
\hline $\mathbf{1 7 6} \mathbf{H f} /{ }^{\mathbf{7 7}} \mathbf{H f}$ & $\mathbf{2 \sigma} \mathbf{S}$. E. & ${ }^{\mathbf{1 7 8}} \mathbf{H f} /{ }^{\mathbf{1 7 7}} \mathbf{H f}$ & $\mathbf{2 \sigma \text { S. E. }}$ \\
\hline 0.282240 & 0.000014 & 1.467247 & 0.000022 \\
0.282231 & 0.000012 & 1.467235 & 0.000030 \\
0.282226 & 0.000011 & 1.467231 & 0.000028 \\
0.282228 & 0.000011 & 1.467259 & 0.000036 \\
0.282233 & 0.000010 & 1.467250 & 0.000038 \\
0.282237 & 0.000012 & 1.467252 & 0.000024 \\
0.282229 & 0.000015 & 1.467251 & 0.000028 \\
0.282215 & 0.000009 & 1.467244 & 0.000028 \\
0.282216 & 0.000015 & 1.467230 & 0.000032 \\
0.282227 & 0.000010 & 1.467258 & 0.000028 \\
Average & & & \\
0.282228 & 0.000005 & 1.467246 & 0.000006 \\
\hline
\end{tabular}




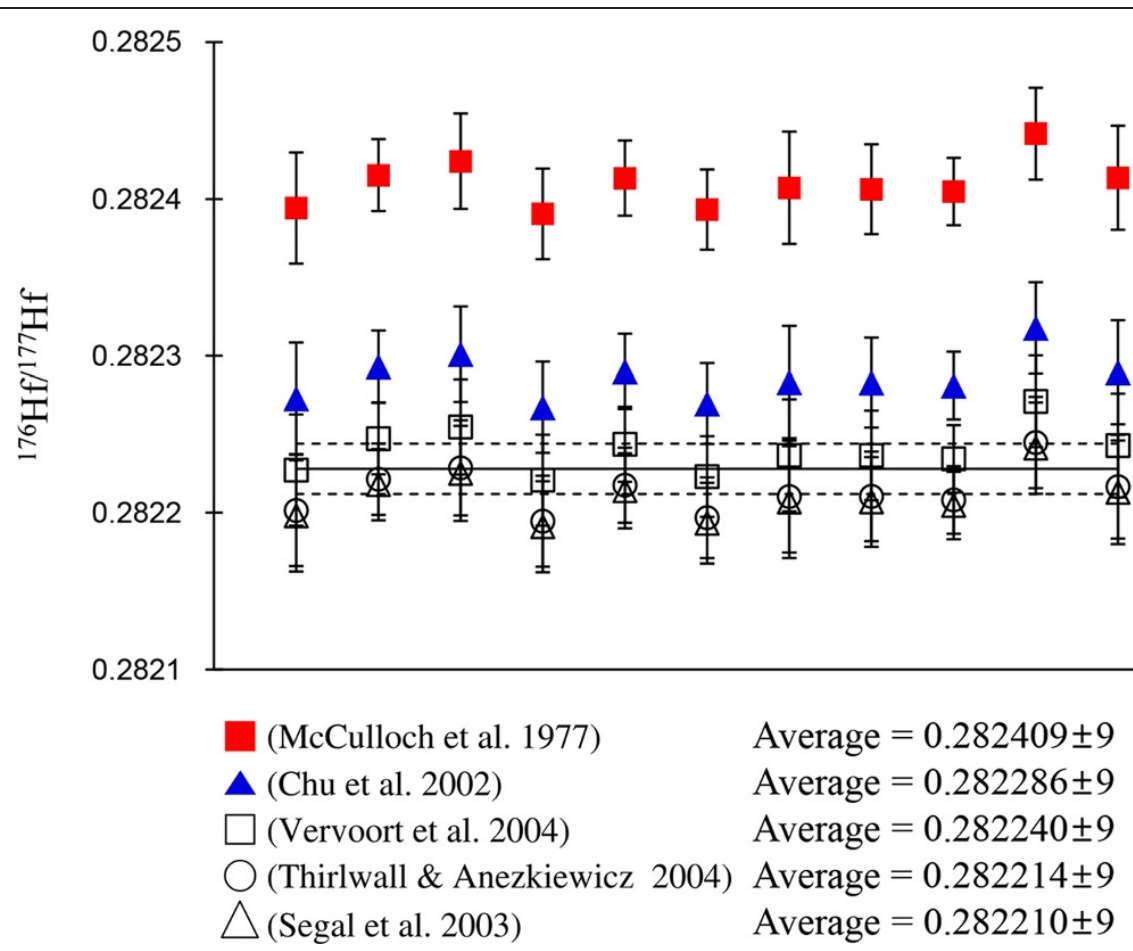

Figure 2 The ${ }^{176} \mathrm{Hf} /{ }^{177} \mathrm{Hf}$ isotopic measurements for a mixed standard solution of which concentrations were $298.7 \mathrm{ng} \mathrm{ml}{ }^{-1}$ for $\mathrm{JMC}^{\mathrm{M}}$ $14375 \mathrm{Hf}, \mathbf{3 0 . 4} \mathrm{ng} \mathrm{ml}^{-1}$ for Accu-Trace Yb and $3.0 \mathrm{ng} \mathrm{ml}^{-1}$ for Accu-Trace Lu. The isobaric interference corrections were made after previous reports on Yb isotopic composition (Chu et al. 2002; McCulloch et al. 1977; Segal et al. 2003; Thirlwall \& Anczkiewicz 2004; Vervoort et al. 2004). Solid and dashed lines respectively represent the average ${ }^{176} \mathrm{Hf} /{ }^{177} \mathrm{Hf}$ of JMC 14375 and $2 \sigma \mathrm{S}$. D. on the mean for the unspiked solution.

Accu-Trace Yb (lot no. B4035064-2B, reference standard) and $3.0 \mathrm{ng} \mathrm{ml}^{-1}$ for Accu-Trace Lu (lot no. B8045141, reference standard). For the calculation of $\beta(\mathrm{Yb})$ and isobaric interference correction, an accurate
$\mathrm{Yb}$ isotopic composition is needed but previous reports are not uniform (Chu et al. 2002; McCulloch et al. 1977; Segal et al. 2003; Thirlwall \& Anczkiewicz 2004; Vervoort et al. 2004). The ${ }^{176} \mathrm{Hf} /{ }^{177} \mathrm{Hf}$ ratio of the

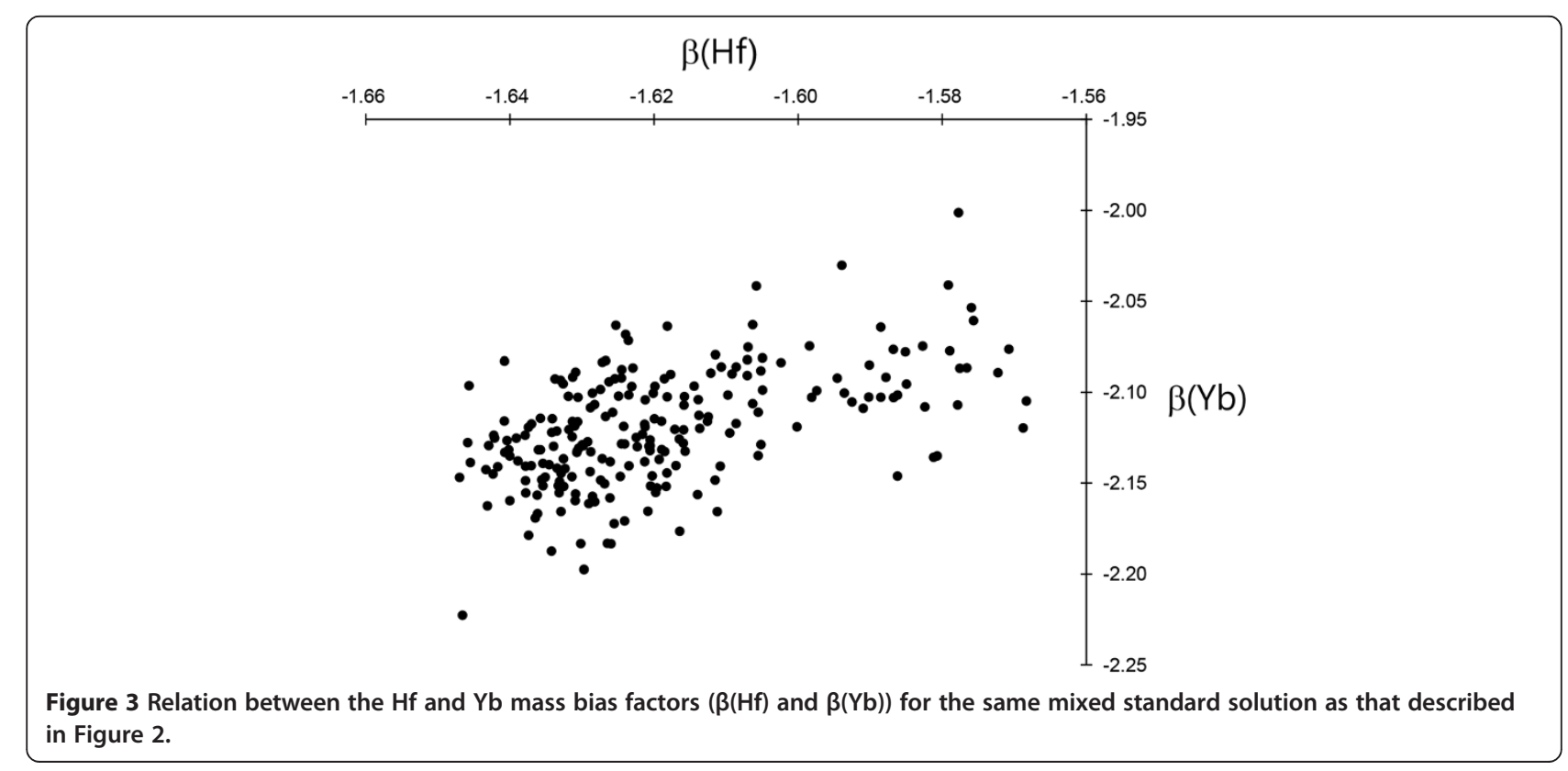


Table 4 Hf-Lu-Yb isotopic data for the mixed standard solutions

\begin{tabular}{|c|c|c|c|c|c|c|}
\hline & ${ }^{176} \mathrm{Hf} /{ }^{177} \mathrm{Hf}$ & $2 \sigma \mathrm{S} . \mathrm{E}$. & ${ }^{176} \mathrm{Lu} /{ }^{177} \mathrm{Hf}$ & $2 \sigma$ S. E. & ${ }^{176} \mathrm{Yb} /{ }^{177} \mathrm{Hf}$ & $2 \sigma \mathrm{S} . \mathrm{E}$. \\
\hline \multicolumn{7}{|c|}{$\mathrm{Hf}=286.2 \mathrm{ng} / \mathrm{ml}$, gravimetric ${ }^{176} \mathrm{Lu} /{ }^{177} \mathrm{Hf}=0.00072,{ }^{176} \mathrm{Yb} /{ }^{177} \mathrm{Hf}=0.03680$} \\
\hline & 0.282214 & 0.000023 & 0.0009273 & 0.0000009 & 0.04969 & 0.00007 \\
\hline & 0.282224 & 0.000024 & 0.0009419 & 0.0000004 & 0.05074 & 0.00003 \\
\hline & 0.282228 & 0.000016 & 0.0009406 & 0.0000005 & 0.05068 & 0.00004 \\
\hline & 0.282246 & 0.000025 & 0.0009408 & 0.0000014 & 0.05071 & 0.00011 \\
\hline & 0.282218 & 0.000022 & 0.0009431 & 0.0000009 & 0.05087 & 0.00007 \\
\hline & 0.282227 & 0.000020 & 0.0009428 & 0.0000005 & 0.05084 & 0.00004 \\
\hline & 0.282237 & 0.000025 & 0.0009438 & 0.0000004 & 0.05093 & 0.00004 \\
\hline & 0.282218 & 0.000024 & 0.0009348 & 0.0000003 & 0.05021 & 0.00002 \\
\hline & 0.282217 & 0.000017 & 0.0009365 & 0.0000006 & 0.05037 & 0.00005 \\
\hline & 0.282228 & 0.000014 & 0.0009397 & 0.0000004 & 0.05055 & 0.00004 \\
\hline Average & 0.282226 & & 0.0009391 & & 0.05056 & \\
\hline $2 \sigma \mathrm{S} . \mathrm{E}$. & 0.000006 & & 0.0000031 & & 0.00024 & \\
\hline \multicolumn{7}{|c|}{$\mathrm{Hf}=298.7 \mathrm{ng} / \mathrm{ml}$, gravimetric ${ }^{176} \mathrm{Lu} /{ }^{177} \mathrm{Hf}=0.00142,{ }^{176} \mathrm{Yb} /{ }^{177} \mathrm{Hf}=0.07170$} \\
\hline & 0.282201 & 0.000036 & 0.001851 & 0.000001 & 0.09813 & 0.00011 \\
\hline & 0.282221 & 0.000023 & 0.001856 & 0.000001 & 0.09855 & 0.00012 \\
\hline & 0.282229 & 0.000030 & 0.001866 & 0.000001 & 0.09932 & 0.00012 \\
\hline & 0.282195 & 0.000029 & 0.001869 & 0.000002 & 0.09954 & 0.00011 \\
\hline & 0.282218 & 0.000024 & 0.001867 & 0.000003 & 0.09942 & 0.00020 \\
\hline & 0.282197 & 0.000026 & 0.001872 & 0.000002 & 0.09975 & 0.00016 \\
\hline & 0.282210 & 0.000036 & 0.001874 & 0.000002 & 0.09992 & 0.00012 \\
\hline & 0.282210 & 0.000029 & 0.001868 & 0.000001 & 0.09944 & 0.00009 \\
\hline & 0.282208 & 0.000022 & 0.001873 & 0.000001 & 0.09983 & 0.00012 \\
\hline & 0.282245 & 0.000029 & 0.001874 & 0.000002 & 0.09994 & 0.00012 \\
\hline & 0.282217 & 0.000033 & 0.001874 & 0.000001 & 0.09995 & 0.00010 \\
\hline Average & 0.282214 & & 0.001868 & & 0.09943 & \\
\hline $2 \sigma \mathrm{S} . \mathrm{E}$. & 0.000009 & & 0.000004 & & 0.00035 & \\
\hline \multicolumn{7}{|c|}{$\mathrm{Hf}=302.8 \mathrm{ng} / \mathrm{ml}$, gravimetric ${ }^{176} \mathrm{Lu} /{ }^{177} \mathrm{Hf}=0.00280,{ }^{176} \mathrm{Yb} /{ }^{177} \mathrm{Hf}=0.14151$} \\
\hline & 0.282207 & 0.000033 & 0.003641 & 0.000003 & 0.19491 & 0.00025 \\
\hline & 0.282216 & 0.000040 & 0.003662 & 0.000004 & 0.19654 & 0.00031 \\
\hline & 0.282215 & 0.000045 & 0.003674 & 0.000004 & 0.19747 & 0.00029 \\
\hline & 0.282185 & 0.000049 & 0.003674 & 0.000004 & 0.19748 & 0.00030 \\
\hline & 0.282195 & 0.000030 & 0.003682 & 0.000002 & 0.19807 & 0.00013 \\
\hline & 0.282206 & 0.000042 & 0.003681 & 0.000002 & 0.19788 & 0.00014 \\
\hline & 0.282222 & 0.000033 & 0.003676 & 0.000003 & 0.19749 & 0.00021 \\
\hline & 0.282196 & 0.000039 & 0.003675 & 0.000004 & 0.19732 & 0.00029 \\
\hline & 0.282233 & 0.000031 & 0.003681 & 0.000003 & 0.19773 & 0.00025 \\
\hline & 0.282184 & 0.000033 & 0.003671 & 0.000004 & 0.19685 & 0.00033 \\
\hline Average & 0.282206 & & 0.003672 & & 0.19717 & \\
\hline $2 \sigma \mathrm{S} . \mathrm{E}$. & 0.000010 & & 0.000008 & & 0.00057 & \\
\hline \multicolumn{7}{|c|}{$\mathrm{Hf}=307.1 \mathrm{ng} / \mathrm{ml}$, gravimetric ${ }^{176} \mathrm{Lu} /{ }^{177} \mathrm{Hf}=0.00413,{ }^{176} \mathrm{Yb} /{ }^{177} \mathrm{Hf}=0.21282$} \\
\hline & 0.282205 & 0.000030 & 0.005275 & 0.000003 & 0.28226 & 0.00022 \\
\hline & 0.282176 & 0.000037 & 0.005289 & 0.000005 & 0.28333 & 0.00036 \\
\hline
\end{tabular}


Table 4 Hf-Lu-Yb isotopic data for the mixed standard solutions (Continued)

\begin{tabular}{|c|c|c|c|c|c|c|}
\hline & 0.282198 & 0.000028 & 0.005289 & 0.000003 & 0.28343 & 0.00026 \\
\hline & 0.282200 & 0.000045 & 0.005298 & 0.000004 & 0.28407 & 0.00029 \\
\hline & 0.282200 & 0.000036 & 0.005300 & 0.000003 & 0.28426 & 0.00021 \\
\hline & 0.282151 & 0.000035 & 0.005308 & 0.000007 & 0.28487 & 0.00051 \\
\hline & 0.282171 & 0.000047 & 0.005296 & 0.000007 & 0.28401 & 0.00051 \\
\hline & 0.282172 & 0.000041 & 0.005315 & 0.000004 & 0.28550 & 0.00030 \\
\hline & 0.282203 & 0.000038 & 0.005233 & 0.000007 & 0.27905 & 0.00052 \\
\hline & 0.282164 & 0.000037 & 0.005281 & 0.000004 & 0.28276 & 0.00026 \\
\hline Average & 0.282184 & & 0.005288 & & 0.28335 & \\
\hline $2 \sigma \mathrm{S} . \mathrm{E}$. & 0.000012 & & 0.000014 & & 0.00111 & \\
\hline
\end{tabular}

mixed standard solution was calculated using different sets of $\mathrm{Yb}$ isotope ratios as the followings.

$$
\begin{aligned}
{ }^{172} \mathrm{Yb} /{ }^{173} \mathrm{Yb}= & 1.35260(\text { Chu et al. 2002), } \\
& 1.35704(\text { McCulloch et al. 1977), } \\
& 1.35428 \text { (Segal et al. 2003), } \\
& 1.35823 \text { (Thirlwall Anczkiewicz 2004), } \\
& 1.35272 \text { (Vervoort et al. 2004) } \\
{ }^{176} \mathrm{Yb} /{ }^{173} \mathrm{Yb}= & 0.79618 \text { (Chu et al. 2002), } \\
& 0.78759 \text { (McCulloch et al. 1977), } \\
& 0.79381 \text { (Segal et al. 2003), } \\
& 0.78696 \text { (Thirlwall Anczkiewicz 2004), } \\
& 0.79631 \text { (Vervoort et al. 2004) }
\end{aligned}
$$

As depicted in Figure 2, the results of 11 measurements $(20$ cycles, integration time $=4.194 \mathrm{~s})$ indicate that reports of $\mathrm{Yb}$ isotope ratios in (Chu et al. 2002; McCulloch et al. 1977) yielded incorrectly high ${ }^{176} \mathrm{Hf} /$ ${ }^{177} \mathrm{Hf}$ ratios. Comparable ${ }^{176} \mathrm{Hf} /{ }^{177} \mathrm{Hf}$ ratios with that of unspiked JMC 14375 Hf $(0.282228 \pm 0.000005)$ could be obtained by using $\mathrm{Yb}$ isotope ratios in (Segal et al. 2003; Thirlwall \& Anczkiewicz 2004; Vervoort et al. 2004), and thus we hereafter give 1.35823 and 0.78696 as the $\left({ }^{172} \mathrm{Yb} /{ }^{173} \mathrm{Yb}\right)_{\text {true }}$ and $\left({ }^{176} \mathrm{Yb} /{ }^{173} \mathrm{Yb}\right)_{\text {true }}$ values, respectively (Thirlwall \& Anczkiewicz 2004) for correcting mass fractionation of $\mathrm{Yb}$ and calculating its isobaric contribution to ${ }^{176} \mathrm{Hf}$. Internal normalization of mass fractionation is not available for $\mathrm{Lu}$, because it has only two natural isotopes $\left({ }^{175} \mathrm{Lu}\right.$ and $\left.{ }^{176} \mathrm{Lu}\right)$. In this study, the $\beta(\mathrm{Lu})$ is assumed to be identical to the $\beta(\mathrm{Hf})$, and $\left({ }^{176} \mathrm{Lu} /{ }^{175} \mathrm{Lu}\right)_{\text {true }}$ of 0.026549 (Chu et al. 2002) is employed to calculate the signal intensities of ${ }^{176} \mathrm{Lu}$. Possible difference between the $\beta(\mathrm{Lu})$ and $\beta(\mathrm{Hf})$ values does not affect the corrected $\mathrm{Hf}$ isotope ratio significantly because the contribution of ${ }^{176} \mathrm{Lu}$ to ${ }^{176} \mathrm{Hf}$ is typically very small in the crustal materials (ca. 1\%, (Rudnick \& Fountain 1995)). The $\beta(\mathrm{Yb})$ value of each cycle is plotted against the $\beta(\mathrm{Hf})$ value in Figure 3 . This diagram confirms that the two values are not identical, and should be measured independently during the run. They are positively correlated with each other but a distinct regression line is not identified.

We further tested the validity of isobaric interference correction described above by using $\mathrm{Hf}+\mathrm{Yb}+\mathrm{Lu}$ solutions mixed with different elemental proportions $\left(\mathrm{Hf}=300 \mathrm{ng} \mathrm{m}{ }^{-1} \mathrm{JMC}\right.$ 14375, Hf:Yb:Lu $\approx 200: 10: 1$, 100:10:1, 50:10:1, 30:9:1). The results with 10 blocks of 20 cycles (integration time $=4.194 \mathrm{~s}$ ) $($ Table 4 ) show that the correction protocol works pretty well. There is, however, a systematic decreasing trend in the corrected ${ }^{176} \mathrm{Hf} /{ }^{177} \mathrm{Hf}$ ratio with increasing $\mathrm{Yb} / \mathrm{Hf}$ ratios, indicating that mass bias is not perfectly corrected by the exponential law for samples high in $\mathrm{Yb}$. The ${ }^{176} \mathrm{Yb} /{ }^{177} \mathrm{Hf}$ and ${ }^{176} \mathrm{Lu} /{ }^{177} \mathrm{Hf}$ ratios are calculated as the followings (Iizuka \& Hirata 2005):

$$
\begin{aligned}
\left({ }^{176} \mathrm{Lu} /{ }^{177} \mathrm{Hf}\right)_{\text {corrected }} & =\left({ }^{176} \mathrm{Lu} /{ }^{175} \mathrm{Lu}\right)_{\text {true }} \times\left({ }^{175} \mathrm{Lu} /{ }^{177} \mathrm{Hf}\right)_{\text {measured }} \\
& \times\left(\mathrm{M}_{177} / \mathrm{M}_{175}\right)^{\beta(\mathrm{Hf})} \\
\left({ }^{176} \mathrm{Yb} /{ }^{177} \mathrm{Hf}\right)_{\text {corrected }} & =\left({ }^{176} \mathrm{Yb} /{ }^{173} \mathrm{Yb}\right)_{\text {true }} \times\left({ }^{173} \mathrm{Yb} /{ }^{177} \mathrm{Hf}\right)_{\text {measured }} \\
& \times\left(\mathrm{M}_{176(\mathrm{Yb})} / \mathrm{M}_{173}\right)^{\beta(\mathrm{Yb})} /\left(\mathrm{M}_{176(\mathrm{Yb})} / \mathrm{M}_{177}\right)^{\beta(\mathrm{Hf})}
\end{aligned}
$$

The calculated ratios are not identical to the gravimetric values (Table 4) due to differences in elemental sensitivity but the two values are quite perfectly correlated with each other $\left(\left({ }^{176} \mathrm{Lu} /{ }^{177} \mathrm{Hf}\right)_{\text {calculated }}=1.277 \times\left({ }^{176} \mathrm{Lu} /\right.\right.$ $\left.{ }^{177} \mathrm{Hf}\right)_{\text {gravimetric; }}\left({ }^{176} \mathrm{Yb} /{ }^{177} \mathrm{Hf}\right)_{\text {calculated }}=1.327 \times\left({ }^{176} \mathrm{Yb} /\right.$ ${ }^{177} \mathrm{Hf}$ ) gravimetric, $\mathrm{R}^{2}>0.98$ ), leaving a possibility that these inter-elemental isotope ratios can be accurately measured directly from the sample solution without chemical purification.

\section{Conclusions}

We tested the capability of a Neptune MC-ICP-MS in obtaining accurate $\mathrm{Hf}$ isotope ratios of the mixed $\mathrm{Hf}+\mathrm{Yb}+\mathrm{Lu}$ standard solution. Careful selection of $\mathrm{Yb}$ isotope compositions was essential for the correction of mass bias and isobaric interferences from $\mathrm{Yb}$ and $\mathrm{Lu}$ on the ${ }^{176} \mathrm{Hf}$ peak. The validity of within-run correction protocol 
described here was confirmed by analyzing a series of mixed standard solutions, although the systematic decreasing trend in the corrected ${ }^{176} \mathrm{Hf} /{ }^{177} \mathrm{Hf}$ ratio with increasing $\mathrm{Yb} / \mathrm{Hf}$ ratios indicated that mass bias was not completely corrected by the exponential law for samples high in $\mathrm{Yb}$. A quite perfect correlation of the calculated ${ }^{176} \mathrm{Yb} /{ }^{177} \mathrm{Hf}$ and ${ }^{176} \mathrm{Lu} /{ }^{177} \mathrm{Hf}$ ratios with the gravimetric values leaves a probability to determine the interelemental isotope ratios directly from the sample solution without chemical separation.

\section{Competing interests}

The authors declare that they have no competing interest.

\section{Authors' contributions}

CSC, JK and HSS designed the study. MSC prepared the sample solutions and carried out isotope measurements. CSC drafted the manuscript. All authors read and approved the final manuscript.

\section{Acknowledgements}

This study was supported by Korea Basic Science Institute grants (G32221, G32210 and (32710). Valuable comments of two anonymous reviewers are acknowledged.

Received: 13 March 2013 Accepted: 13 March 2013

Published: 18 April 2013

\section{References}

Blichert-Toft J, Chauvel C, Albarede F (1997) Separation of Hf and Lu for highprecision isotope analysis of rock samples by magnetic sector-multiple collector ICP-MS. Contrib. Mineral. Petrol. 127:248-260

Chu NC, Taylor RN, Chavagnac V, Nesbitt RW, Boella M, Milton JA (2002) Hf isotope ratio analysis using multi-collector inductively coupled plasma mass spectrometry: an evaluation of isobaric interference corrections. J. Anal. At. Spectrom. 17:1567-1574

Griffin WL, Pearson NJ, Belousova EA, Jackson SE, O'Reily SY, van Achterberg E, Shee SR (2000) The Hf-isotopie composition of cratonic mantle: LAM-MCICPMS analysis of zircon megacrysts in kimberlites. Geochim. Cosmochim. Acta. 64:133-147

Hawkesworth CJ, Kemp AIS (2006) Using hafnium and oxygen isotopes in zircons to unravel the record of crustal evolution. Chem. Geol. 226:144-162

lizuka T, Hirata T (2005) Improvements of precision and accuracy in in situ Hf isotope microanalysis of zircon using the laser ablation-MC-ICPMS technique. Chem. Geol. 220:121-137

McCulloch MT, Rosman KJR, De Laeter JR (1977) The isotopic and elemental abundance of ytterbium in meteorites and terrestrial samples. Geochim. Cosmochim. Acta. 41:1703-1707

Nowell GM, Kempton PD, Noble SR, Fitton JG, Saunders AD, Mahoney JJ, Taylor RN (1998) High precision Hf isotope measurements of MORB and OIB by thermal ionization mass spectrometry: insights into the depleted mantle. Chem. Geol. 149:211-233

Patchett PJ (1983) Importance of the Lu-Hf isotopic system in studies of planetary chronology and chemical evolution. Geochim. Cosmochim. Acta. 47:81-91

Patchett PJ, Tatsumoto M (1980) Hafnium isotope variations in oceanic basalts. Geophy. Res. Lett. 7:1077-1080

Patchett PJ, Kouvo O, Hedge CE, Tatsumoto M (1981) Evolution of continental crust and mantle heterogeneity: evidence from $\mathrm{Hf}$ isotopes. Contrib. Mineral. Petrol. 78:279-297

Rudnick RL, Fountain DM (1995) Nature and composition of the continental crust: A lower crustal perspective. Rev. Geophys. 33:267-309

Russel WA, Papanastassiou DA, Tombrello TA (1978) Ca isotope fractionation on the earth and other solar system materials. Geochim. Cosmochim. Acta. 42:1075-1090

Scherer E, Münker C, Mezger K (2001) Calibration of the lutetium-hafnium clock. Science. 293:683-687

Segal I, Halicz L, Platzner IT (2003) Accurate isotope ratio measurements of ytterbium by multi-collector inductively coupled plasma mass spectrometry applying erbium and hafnium in an improved double external normalization procedure. J. Anal. At. Spectrom. 18:1217-1223

Thirlwall MF, Anczkiewicz R (2004) Multidynamic isotope ratio analysis using MCICP-MS and the causes of secular drift in $\mathrm{Hf}, \mathrm{Nd}$ and $\mathrm{Pb}$ isotope ratios. Int. J. Mass Spectrom. 235:59-81

Thirlwall MF, Walder AJ (1995) In-situ hafnium isotope ratio analysis of zircon by inductively coupled plasma multiple collector mass spectrometry. Chem. Geol. 122:241-247

Vervoort JD, Blichert-Toft J (1999) Evolution of the depleted mantle: Hf isotope evidence from juvenile rocks through time. Geochim. Cosmochim. Acta. 63:533-556

Vervoort JD, Patchett PJ, Söderlund U, Baker M (2004) Isotopic composition of Yb and the determination of Lu concentrations and $\mathrm{Lu} / \mathrm{Hf}$ ratios by isotope dilution using MC-ICPMS. Geochem. Geophys. Geosystem. 5, Q11002. doi:10.1029/2004GC000721

Woodhead J, Hergt J, Shelley M, Eggins S, Kemp R (2004) Zircon Hf-isotope analysis with an excimer laser, depth profiling, ablation of complex geometries, and concomitant age estimation. Chem. Geol. 209:121-135

doi:10.1186/2093-3371-4-1

Cite this article as: Choi et al:: Hafnium isotope analysis of mixed standard solutions by multi-collector inductively coupled plasma mass spectrometry: an evaluation of isobaric interference corrections. Journal of Analytical Science and Technology 2013 4:1.

\section{Submit your manuscript to a SpringerOpen ${ }^{\odot}$ journal and benefit from:}

- Convenient online submission

- Rigorous peer review

- Immediate publication on acceptance

- Open access: articles freely available online

- High visibility within the field

- Retaining the copyright to your article

Submit your next manuscript at $\gg$ springeropen.com 